\title{
Anterior cingulate cortex disconnectivity in high-risk offspring of bipolar patients: a preliminary DTI study
}

\author{
Mert Besenek $^{1}$, Inci Turkan Yilmaz ${ }^{2}$, Handan Guleryuz $z^{2}$, Sevay Alsen Guney ${ }^{2}$, Neslihan Inal Emiroglu² \\ 'Dokuz Eylül University, School of Medicine, Department of Child and Adolescent Psychiatry, İzmir - Turkey \\ ${ }^{2}$ Dokuz Eylül University, School of Medicine, Department of Radiodiagnostics, İzmir - Turkey
}

\begin{abstract}
Objective: Given the shortage of studies done in this field, our aim was to distinguish offspring of bipolar parents between symptomatic and asymptomatic, then to compare neuroimaging findings between groups, thus assessing the early biomarker potential of neuroimaging techniques.

Method: In this case-controlled study, we compared an asymptomatic high-risk group and a symptomatic high-risk group with a healthy control group. Diffusion tensor imaging (DTI) with region of interest (ROI) was used to analyze mean diffusivity (MD) and fractional anisotropy (FA) values in the superior longitudinal fasciculus (SLF) of the frontal cortex, the genu and splenium of the corpus callosum (CC), the cingulum bundle of the anterior cingulate cortex (CB-aCC), and the uncinate fasciculus (UF).

Results: No differences were found between groups for FA and MD in the CC, SLF, and UF, but MD of the CB-aCC was significantly higher in the AHR and SHR groups than in healthy controls. Higher MD values found in the aCC of the high-risk groups may represent cellular damage in that region, regardless of symptomatic status.

Conclusion: Results from this study may suggest candidates that could contribute to the neural underpinnings of a bipolar prodromal phase. Further longitudinal studies with larger sample sizes are needed to map the association of neural development and bipolar disorder-related psychopathology in at-risk youth.
\end{abstract}

Keywords: Anterior cingulate cortex, bipolar disorder, diffusion tensor imaging, mean diffusivity

\section{INTRODUCTION}

Bipolar disorder (BD) is defined as a chronic mood disorder that may severely disrupt an individual's academic, professional, family, and social functioning (1). In general, BD tends to have an onset towards the end of adolescence and the beginning of early adulthood, affecting $0.6-2.4 \%$ of the general population (2) and $1.2 \%$ of children and adolescents $(3,4)$. Although $\mathrm{BD}$ is known as a disorder with a strong genetic predisposition, no biological marker for the diagnosis has yet been identified; the diagnosis mostly relies on clinical methods. This may be among the reasons for a delay of up to ten years in the correct identification of $\mathrm{BD}$ following its onset (5) and for misdiagnoses in $40-70 \%$ of patients (6). Recent studies have increasingly emphasized the importance of early diagnosis and treatment of psychiatric disorders. "Early and correct" diagnosis and treatment in youth with mood disorders potentially enable children to

How to cite this article: Besenek M, Yilmaz IT, Guleryuz H, Alsen Guney S, Inal Emiroglu N. Anterior cingulate cortex disconnectivity in high-risk offspring of bipolar patients: a preliminary DTI study. Dusunen Adam The Journal of Psychiatry and Neurological Sciences 2019;32:203-213.

Correspondence: Mert Besenek, Dokuz Eylül University, School of Medicine, Department of Child and Adolescent Psychiatry, İzmir - Turkey Phone: +90 4642130491 E-mail: mbesenek1989@gmail.com 
follow a normative developmental path, prevent an unrecoverable loss in the children's psychosocial development and education, and decrease suicide risk $(7,8)$. To determine BD in its early phases and work out biological risk factors, various studies have been conducted among high-risk (HR) groups, covering fields of clinical, genetic, neurocognition, and neuroimaging research (9). A positive history for $\mathrm{BD}$ in first-degree relatives has been identified as the biggest single risk factor increasing the odds of developing a mood disorder $(10,11)$. In a study $(10,12)$ where children of patients diagnosed with $\mathrm{BD}$ were followed for fifteen years, Duffy et al. (10) found that the genetically HR group had higher rates of anxiety, sleep, alcohol/substance use, and depressive disorders compared to the control group. The same study also showed that the risk of developing mood disorders in genetically HR groups was 2.1-fold larger for patients diagnosed with anxiety disorder and 2.4-fold for those with alcohol/substance use disorder. Therefore, assessing the offspring of parents diagnosed with $\mathrm{BD}$, who are at an increased risk for developing mood disorders, may enable us to identify initial abnormalities and vulnerability factors within this group (10).

Diffusion tensor imaging (DTI) has been increasingly used in recognition of its superior ability to provide a very detailed exploration of micro-structural characteristics of the brain's white matter (13). DTI is an MRI-based neuroimaging technique that allows estimating the location, orientation, and anisotropy of the brain's white matter by measuring the diffusion capacity of the water molecules in the brain. The most important data obtained by the use of DTI are fractional anisotropy (FA) and mean diffusivity (MD) values, which reflect the myelinization and integrity of the pathways in the white matter. Lower FA values and higher MD values may indicate myelinization damage within zones and pathways that constitute the white matter or disrupted connections (14). DTI studies conducted to gain a better understanding of BD pathophysiology generally indicate decreased levels of FA within the frontal area (15-17), the corpus callosum (18-20), and the cingulum (20). In a meta-analysis that covered the voxel-based DTI studies by Ellison-Wright and Bullmore (21), the anterior cingulate cortex (aCC) was identified as one of the most prominent brain regions to be affected in $\mathrm{BD}$ patients. Apart from many critical functions, including learning, emotion control, and consciousness, the most relevant and identifiable roles of the aCC are error detection and conflict monitoring. In studies evaluating responses to emotional stimuli, the aCC was found to be much more active in BD patients than in healthy controls (22). It has been postulated that disruptions in emotional regulation developing as a result of hyperactivation of the aCC are related to $\mathrm{BD}(20)$.

The aCC is considered to be a part of the ventrallimbic connections undergoing limited inhibition by the cognitive network. The uncinate fasciculus (UF) has been identified as the pathway that links limbic system regions (e.g., the amygdala and the hippocampus) to certain parts of the frontal lobe, including the ventral prefrontal cortex (vPFC) and the orbitofrontal cortex (OFC). Moreover, the UF is also responsible for connecting the aCC to regions of the amygdala and hippocampal areas that are linked to attention (19), memory (23), and emotional regulation $(24,25)$. Neuroimaging studies conducted with adult BD patients have demonstrated an increased fiber density specifically in the left UF of BD patients, compared to a control group $(26,27)$. This measured increase in UF density may be suggestive of extreme affective conditions and, in general, an overactive emotional neural system related to emotional instability. Since the UF is significant as a connection between regions that are important in the pathophysiology of BD, it may be one of the structural white-matter regions affected in the course of $\mathrm{BD}$.

Although there have been numerous DTI studies of BD patients, research exploring DTI characteristics of HR offspring of BD patients has been scarce. A very recent study by Versace et al. done using a tract-based spatial statistic method found higher FA and lower MD values for the corpus callosum and right inferior longitudinal fasciculus (ILF) in HR groups than in healthy controls (28). Another study including HR offspring along with $\mathrm{BD}$-diagnosed children and healthy controls showed that BD children had lower FA values in the cingulate-paracingulate cortex than those in the HR group, whereas the HR group had lower FA values in the superior longitudinal fasciculus (SLF) than the healthy controls (17). The study by Versace et al. (28) quoted above compared the diffusion imaging markers between offspring of BD parents, offspring of parents diagnosed with other psychopathologies (major depression and attention-deficit/hyperactivity disorder), and healthy controls. They found lower FA values in the left cingulum, left ILF, and left forceps minor and higher FA values in right UF and IFL of both offspring groups compared the healthy controls, whereas lower FA values in SLF compared to healthy 
controls were observed only in the offspring of BD parents (28).

Given the shortage of studies in this field, our primary objective was to compare the symptomatic and asymptomatic offspring of bipolar parents (at least one parent with BD) with healthy controls to identify differences between groups in brain white matter. The aim was to identify structural biomarkers of illness that would help in the early recognition of $\mathrm{BD}$ among children at a high risk of developing BD. The hypotheses for the study were: 1) we expected finding lower FA values and $M D$ values in the superior longitudinal fasciculus (SLF) of the frontal cortex and in the genu and splenium regions of the corpus callosum in the HR groups compared to the healthy controls due to cellular damage playing an important role in the pathophysiology of $\mathrm{BD} ; 2$ ) differences in $\mathrm{FA}$ and $\mathrm{MD}$ should be much more conspicuous in the symptomatic high-risk (SHR) group than in the asymptomatic highrisk (AHR) group; and 3) FA values should be higher and MD values lower in HR groups than in healthy controls, being much more pronounced in the SHR than in the AHR group, due to hyperactivation of related pathways through possible compensatory mechanisms caused by hyperstimulation of aCC and UF regions, which is defined as the major psychopathological disruption in $\mathrm{BD}$ according to the literature.

\section{METHOD}

\section{Participants}

\section{High-Risk (HR) Group}

In this case-control study, the high-risk (HR) group included 13-18-year-old children of parents with BD Type I or II who were followed by the Adult Psychiatry Department of Dokuz Eylul University, and 13-18-yearold offspring of parents with BD Type I or II who had presented to the Child and Adolescent Psychiatry Department of Dokuz Eylul University. All parents were assessed by a Structured Clinical Interview for the DSM-IV Axis I Disorders (SCID-I) (29) to confirm a diagnosis of $\mathrm{BD}$ or to diagnose any other psychiatric disorders. Children aged 13-18 years who had at least one parent diagnosed with BD Type I or II were administered the Schedule for Affective Disorders and Schizophrenia for School Aged Children - Present and Lifetime Version (K-SADS-PL) (30), and according to the collected data, the HR group was divided into two subgroups: symptomatic high-risk (SHR) and asymptomatic high-risk (AHR).

\section{Symptomatic High-Risk (SHR) Group}

This group comprised high-risk individuals that had a diagnosis of a psychiatric disorder or relevant history of symptoms determined by K-SADS-PL completed within the past six months, not including substance/ alcohol abuse or dependency, BD (type I or II), schizophrenia, delusional disorder, schizoaffective disorder, schizophreniform disorder, and pervasive developmental disorder. These SHR children had to be in remission for at least three months. For individuals with a history of depressive disorder, a score on the Children's Depression Rating ScaleRevised (CDRS-R) $\leq 54$ was used as a cutoff point; for children with an anxiety disorder, a State Trait Anxiety Inventory (STAI) score <39; and for participants with a history of BD-NOS, a CDRS-R score $\leq 54$ and a Young Mania Rating Scale (YMRS) score $\leq 7$. This requirement allowed for a better distinction between the early psychopathology of BD and other psychopathologies and full-blown BD psychopathology $(31,32)$.

\section{Asymptomatic High-Risk (ASH) Group}

This group comprised high-risk individuals who were not diagnosed with any psychiatric disorder at the time of the study and had not met any criteria for a psychiatric diagnosis during their lifetime, as determined by the K-SADS-PL interview.

\section{Healthy Control (HC) Group}

This group comprised children who did not meet the criteria for any psychiatric disorder according to the K-SADS-PL interview, whose parents did not have any psychiatric disorder according to the SCID-I interview, and who did not have any history of headache, head trauma, or neurological disease. They were matched by gender and educational level to the offspring of bipolar parents. To recruit healthy volunteers to participate in the study, written announcements and notices providing more information on the study were posted around the hospital. All children who applied were assessed, reviewing inclusion and exclusion criteria for each volunteer, and persons who met the criteria were included in the study. In addition, upon giving written consent, residents of the catchment area of the study who had presented to other outpatient units for nonrelated health problems and met the inclusion criteria while not falling under the exclusion criteria were also assigned to the $\mathrm{HC}$ group.

This study was approved by the Institutional Review Board (Ethics Committee) of Dokuz Eylul 
University School of Medicine (Izmir, Turkey) and has been carried out in accordance with the ethical standards laid down in the revised version of the World Medical Association's Declaration of HelsinkiEthical Principles for Medical Research Involving Human Subjects and its later amendments. All parents of the children had given assent and written consent for the children to participate in the study as either healthy volunteers or case group members after the procedures had been fully explained.

\section{Exclusion Criteria}

\section{Excluded From the Study Were}

- Patients with neurodegenerative diseases, mental retardation (IQ below 70), epilepsy, cerebral tumor or cerebro-vascular diseases, or a history of blackout due to head trauma,

- Patients with psychiatric disorders who were not in remission during the study, had taken drugs in the last 48 hours that might affect neurocognitive tests (benzodiazepines, psychostimulants, alcohol) or had health issues that interfere with the MR process (pacemakers),

- Patients with a diagnosis of BD type I or II, schizophrenia, delusional disorder, schizoaffective disorder or schizophreniform disorder, and

- Patients who did not give written consent.

\section{MRI Acquisition and Processing}

All MRI data were acquired with a $1.5 \mathrm{~T}$ unit (Gyroscan Achieva, release 8.1; Philips Medical Systems, Lakewood, CO, USA), including threedimensional T1-weighted (3D T1) spoiled gradientrecalled (time to repetition [TR]/time to echo [TE], 25/30; flip angle, $30^{\circ}$; field of view [FOV], 200x200 $\mathrm{mm}^{2}$; slice thickness, $2 \mathrm{~mm}$; gap, $\left.1 \mathrm{~mm}\right), 3 \mathrm{D} \mathrm{T} 1$ inversion recovery (IR) (TR/TE, 2016/14; IR delay, $390 \mathrm{~ms}$; FOV, 200x200 $\mathrm{mm}^{2}$; slice thickness, $2 \mathrm{~mm}$; gap, $1 \mathrm{~mm}$ ), and DTI sequences. DTI was obtained by using a dedicated 8-channel head coil and a multirepetition single-shot echo-planar sequence with a section thickness of $5 \mathrm{~mm}$ without a gap. The DTI images were obtained in 32 gradient directions with a sensitivity of $b=1000 \mathrm{~s} / \mathrm{mm}^{2}, T R=3464 \mathrm{~ms}, T E=89 \mathrm{~ms}$, $\mathrm{NEX}=1, \mathrm{FOV}=230 \times 230 \mathrm{~mm}^{2}$, and a matrix of $112 \times 128$. Acquisition time was 7 minutes 42 seconds.

DTI processing and correction for motion and eddy currents was done with FMRIB software, which is included in FSL (FMRIB Software Library, http://www. fmrib.ox.ac.uh/fsl/). To remove non-brain tissue images from the brain images, 0.3 fractional intensity was set as a threshold on the Brain Extraction Tool (BET). FA maps and diffusion tensor matrices were created with BioImage Suite Software (http://www.bioimagesuite. org). The FA and MD values were measured with the region of interest (ROI) method from the points located in brain white matter. The ROI zones were chosen a priori according to the literature (15-20), then defined bilaterally and sized symmetrically according to the anatomical regions, with ROIs of voxel sizes of 10-15 pixels in width. These width sizes were similar to those in other DTI studies in which ROI was used (33). Circular ROI of specific sizes were manually placed in predetermined anatomic locations in both hemispheres, including SLF, genu and splenium of the corpus callosum, the cingulum bundle of aCC (CB-aCC), and UF (Figures 1 and 2).

\section{Statistical Analysis}

Statistical Analysis of Socio-demographic and Clinic Data

All statistical analyses were performed using SPSS version 24 . Pearson's chi-square $\left(\chi^{2}\right)$ test was used to determine differences of categorical variables between groups and for the evaluation of continuous variables. Shapiro-Wilk and Levene tests were used to assess whether the data fit normal distribution, and according to their appropriateness to normal

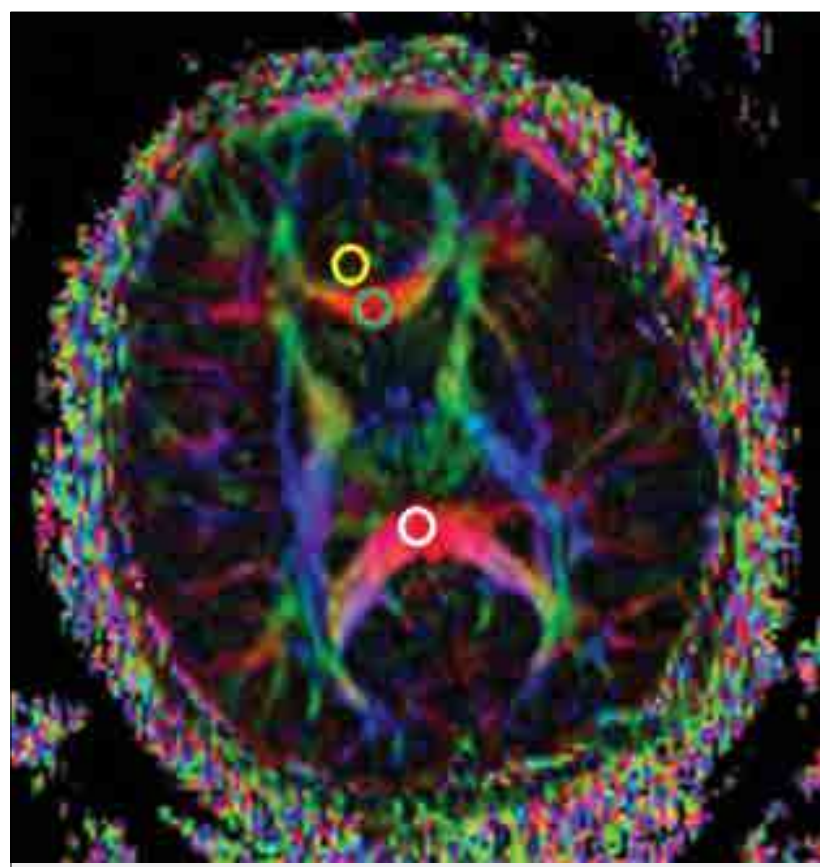

Figure 1. Anterior Cingulate Cortex and Corpus Callosum areas on the DTI image.

Yellow circle: Cingulum Bundle of Anterior Cingulate Cortex Green circle: Genu of Corpus Callosum

White circle: Splenium of Corpus Callosum 


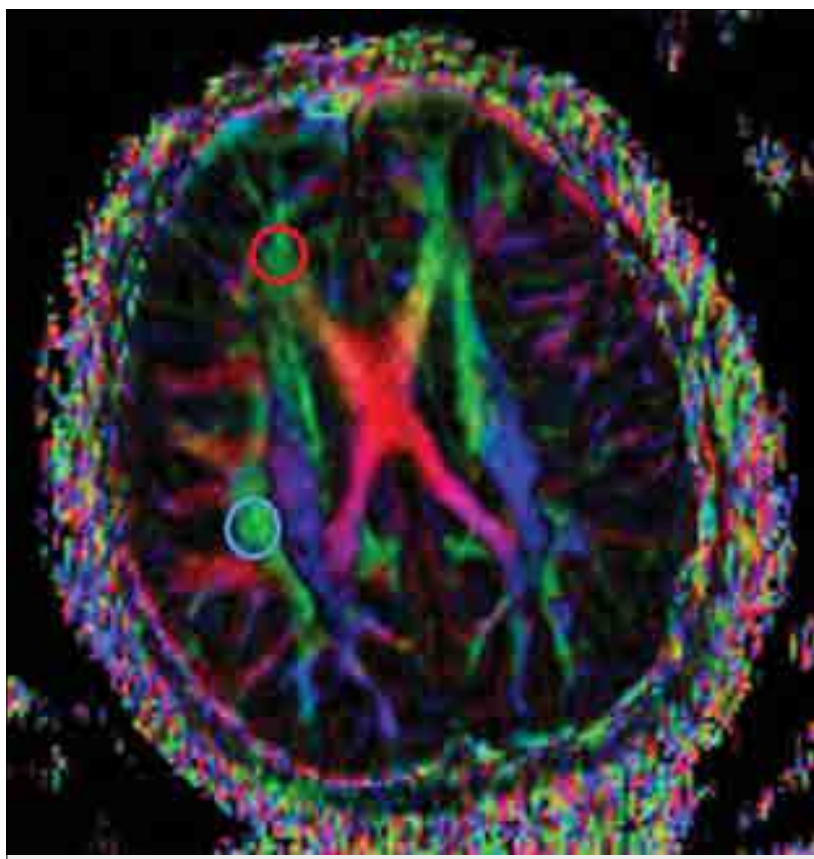

Figure 2. Superior Longitudinal Fasciculus and Uncinate Fasciculus on the DTI image.

Red circle: Uncinate Fasciculus

Blue circle: Superior Longitudinal Fasciculus

distribution, Kruskal-Wallis or ANOVA was used for multiple-group comparisons. An independent twotailed t-test or Mann-Whitney U test was used for the analysis of paired groups. When a statistical difference was found between the means of triadic groups, to determine the main group that had caused the difference, pair-wise analysis was used for the KruskalWallis test, while Bonferroni analysis was performed for the ANOVA method. Bonferroni correction was applied when calculating the $\mathrm{p}$ value for statistical significance in multiple comparisons. Pearson's correlation coefficient test was used to compare the normally distributed data and Spearman's rank correlation coefficient test was used to compare the non-normally distributed data. Multiple linear regression analysis was used to investigate the effect of the possible confounding factors on the statistically significant correlations.

\section{Statistical Analysis of DTI Data}

To calculate the between-group differences of FA values assessed for each pathway, ROI data were examined for normalcy. Then Kruskal Wallis or ANOVA test were used within triadic groups, while Independent t-test or Mann-Whitney $U$ analyses were performed in paired groups. When a statistical difference was found between the means of triadic groups, to determine the main group that had caused the difference, pair-wise analysis was used for the Kruskal-Wallis test, while Bonferroni analysis was performed for the ANOVA method.

For all statistical analyses, a $\mathrm{p}$ value $<0.05$ was set as statistically significant. Bonferroni correction was applied when calculating the $\mathrm{p}$ value for statistical significance in multiple comparisons. Means and standard deviations are given for normally distributed variables. Medians and interquartile ranges are presented for non-normally distributed variables. Numbers and percentages are given for categorical variables.

\section{RESULTS}

\section{Demographic Characteristics of the Participants}

A total of 15 SHR and 9 AHR offspring were referred and assessed during the six-month referral period of the study. Two subjects from the SHR group were excluded because they met the criteria for major depressive disorder at the time of the interviews. One subject from the AHR group and one subject from the SHR group had dental braces, so DTI could not be performed on them. For one subject from the AHR group, the neuroimaging data was corrupted and could not be analyzed. In the end, neuroimaging data of 12 SHR and 7 AHR offspring (a total of 19 subjects in the HR groups) were included in the study. A total of 19 subjects in the HC group participated in the study. Age (months and years), sex, educational level, socioeconomic status, and hand dominance were analyzed between groups and the results are shown in Tables 1 and 2. Significant differences in age were found between paired groups (HR/HC; $\mathrm{p}=0.027$; Table 2). Upon pairwise analysis, it was found that the actual age difference between the three groups originated from the AHR/HC comparison $(\mathrm{p}=0.016, \mathrm{AHR}<\mathrm{HC})$. When age groups were regarded as categorical data, statistically significant differences were found between the triadic groups $(\mathrm{p}<0.01)$ but not between dyadic groups $(\mathrm{p}=0.072$; Tables 1 and 2). Consistent with these age differences between groups, all subjects in the AHR group were at the pre-high school educational level, thus leading to a statistically significant difference between the three groups in educational level ( $\mathrm{p}=0.003$; Table 1$)$.

\section{Psychiatric Characteristics of the Participants}

In the assessment period of the study, the psychiatric status and background of subjects in the SHR group were determined, including current and past diagnoses/ symptoms and medications that had been/were being used. Most frequently seen in SHR subjects, both in the 
Table 1: Comparing the demographic characteristics between triadic groups

\begin{tabular}{|c|c|c|c|c|c|}
\hline & SHR & AHR & $\mathrm{HC}$ & $\chi^{2}$ & p* \\
\hline Number of participants & 12 & 7 & 19 & & \\
\hline $\begin{array}{l}\text { Median values of age in months } \\
\text { (Interquartile range) }\end{array}$ & $193(47)$ & $161(13)$ & $209(43.5)$ & 7.772 & $0.021^{\mathrm{a}}$ \\
\hline \multicolumn{6}{|l|}{ Age categories (Years) } \\
\hline $12-15$ & 5 & 7 & 7 & \multirow{2}{*}{9.256} & \multirow{2}{*}{$0.01^{b}$} \\
\hline $16-18$ & 7 & 0 & 12 & & \\
\hline \multicolumn{6}{|l|}{ Sex } \\
\hline Male & 7 & 3 & 13 & \multirow{2}{*}{2.395} & \multirow{2}{*}{$0.302^{b}$} \\
\hline Female & 5 & 4 & 6 & & \\
\hline \multicolumn{6}{|l|}{ Socio-economic status } \\
\hline Good & 3 & 1 & 9 & \multirow{3}{*}{4.350} & \multirow{3}{*}{$0.361^{\mathrm{b}}$} \\
\hline Average & 7 & 5 & 6 & & \\
\hline Bad & 2 & 1 & 4 & & \\
\hline \multicolumn{6}{|l|}{ Education } \\
\hline$<$ High-School & 4 & 7 & 6 & \multirow{2}{*}{11.787} & \multirow{2}{*}{$0.003^{b}$} \\
\hline$>$ High-School & 8 & 0 & 13 & & \\
\hline
\end{tabular}

SHR: Symptomatic high-risk group, AHR: Asymptomatic high-risk group, HC: Healthy control group, akruskal-Wallis test was used for data analysis, ${ }^{\mathrm{b} P e a r s o n}$ Chi Square test was used for data analysis, $\mathrm{p}<0.016$ was accepted as statistically significant after Bonferroni correction

Table 2: Comparing the demographic characteristics between paired groups

\begin{tabular}{|c|c|c|c|c|}
\hline & $H R(n=19)$ & $H C(n=19)$ & $x^{2}$ & $\mathbf{p}$ \\
\hline $\begin{array}{l}\text { Median values of age in months } \\
\text { (Interquartile range) }\end{array}$ & $171(38)$ & $209(43.5)$ & 4.900 & $0.027^{a}$ \\
\hline \multicolumn{5}{|l|}{ Age categories (Years) } \\
\hline $12-15$ & 12 & 7 & \multirow{2}{*}{3.209} & \multirow{2}{*}{$0.072^{b}$} \\
\hline $16-18$ & 7 & 12 & & \\
\hline \multicolumn{5}{|l|}{ Sex } \\
\hline Male & 10 & 13 & \multirow{2}{*}{1.943} & \multirow{2}{*}{$0.163^{b}$} \\
\hline Female & 9 & 6 & & \\
\hline \multicolumn{5}{|l|}{ Education } \\
\hline$<$ High-School & 11 & 6 & \multirow{2}{*}{3.802} & \multirow{2}{*}{$0.051^{b}$} \\
\hline >High-School & 8 & 13 & & \\
\hline \multicolumn{5}{|l|}{ Socio-economic status } \\
\hline Good & 3 & 4 & \multirow{3}{*}{4.035} & \multirow{3}{*}{$0.133^{b}$} \\
\hline Average & 12 & 6 & & \\
\hline Bad & 4 & 9 & & \\
\hline \multicolumn{5}{|l|}{ Hand dominance } \\
\hline Right & 14 & 13 & \multirow{2}{*}{0.043} & \multirow{2}{*}{$0.835^{b}$} \\
\hline Left & 5 & 6 & & \\
\hline
\end{tabular}

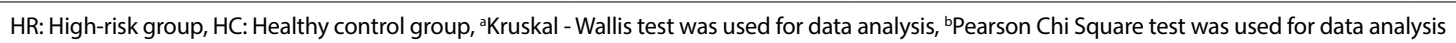

past and at the time of the study, were subsyndromal symptoms (33\% and $66,5 \%$ respectively), followed by a diagnosis of major depressive disorder in the past $(42 \%)$. The majority of the SHR subjects were unmedicated (75\%) (Table 3).

\section{Participants' Neuroimaging Characteristics}

FA values of all relevant brain regions showed no statistically significant difference when comparing two groups (HR/HC) or three groups (SHR/AHR/HC). Similarly, no significant difference in MD values was 
Table 3: Psychiatric assessment of the symptomatic high-risk group

\begin{tabular}{lcc} 
SHR (n=12) & In the past & $\begin{array}{c}\text { At the time } \\
\text { of the study }\end{array}$ \\
\hline Psychiatric diagnosis & - & $2(16.75 \%)$ \\
ADHD & $5(42 \%)$ & - \\
MDD & $2(16.5 \%)$ & - \\
AD & $1(8.5 \%)$ & - \\
CD & - & $2(16.75 \%)$ \\
DMDD & $4(33 \%)$ & $8(66.5 \%)$ \\
Subsyndromal symptoms & & \\
Medications used & $2(16.75 \%)$ & - \\
Antidepressant & $2(16.75 \%)$ & $1(8.33 \%)$ \\
AAP & - & $1(8.33 \%)$ \\
MS+AAP & $3(25 \%)$ & $1(8.33 \%)$ \\
Stimulant & $5(41.5 \%)$ & $9(75 \%)$ \\
Unmedicated &
\end{tabular}

SHR: Symptomatic high-risk group, ADHD: Attention deficit/hyperactivity disorder, MDD: Major depressive disorder, AD: Anxiety disorder, CD: Conduct disorder, DMDD: Disruptive mood dysregulation disorder, AAP: Atypical antipsychotics, MS: Mood stabilizer

found when two groups (HR/HC) or three groups (SHR/AHR/HC) were compared by relevant brain regions, except for $\mathrm{CB}-\mathrm{aCC} \mathrm{MD}$ values (Table 4). Mann-Whitney $\mathrm{U}$ analysis of $\mathrm{CB}-\mathrm{aCC}$ MD values showed that there was a statistically significant difference between values for SHR and HC subjects (SHR MD values $>$ HC MD values; $\mathrm{p}=0.014$ ) and between values for $\mathrm{HR}$ and $\mathrm{HC}$ (HR MD values $>\mathrm{HC}$ MD values; $p=0.01)$. Even though no statistically significant difference of $\mathrm{CB}$-aCC MD values was found between SHR and AHR groups ( $\mathrm{p}=0.837$ ), there may be a trend towards a significant difference between AHR and $\mathrm{HC}$ groups (AHR values $>\mathrm{HC}$ values; $\mathrm{p}=0.037$ ) (Table 4). No relationship between significantly different data of the groups (age and education level) and CB-aCC MD values was found in correlation and regression analyses (Spearman's rank correlation coefficient test, $p=0.072$ for age and $p=0.062$ for education level; multiple linear regression analysis, $\mathrm{p}=0.471$ and $95 \%$ confidence interval: $-0.352-0.167$ for age; $\mathrm{p}=0.933$ and $95 \%$ confidence interval: $-0.006-0.005$ for education level).

\section{DISCUSSION}

The aim of this study was to determine the DTI characteristics (including MD and FA values) of five brain regions in offspring of $\mathrm{BD}$ patients and to establish if these values can distinguish between symptomatic and asymptomatic high-risk children, thus defining the potential for a use of neuroimaging methods as a biomarker that would help in early recognition of $\mathrm{BD}$ among children at a high risk of developing the disease. FA values of SLF, corpus callosum (splenium and genu), $\mathrm{CB}-\mathrm{aCC}$, and UF regions were compared between groups; however, it was not possible to reach a statistically significant result. MD values were also assessed for the same regions. MD is calculated by dividing the total quantity of diffusion covered by water molecules within a three-dimensional medium in all three axes (eigenvector) by three. MD values are, in general, inversely correlated with FA values; water molecules are found in higher quantities in regions with myelin damage or disrupted connectivity, as they diffuse more easily. Our hypothesis was that FA values would be higher and MD values lower in CB-aCC and UF regions of HR compared to healthy controls, being much more pronounced among SHR compared to AHR. By contrast, we found significantly higher $\mathrm{MD}$ values of $\mathrm{CB}-\mathrm{aCC}$ in $\mathrm{HR}$ offspring. MD values for the SHR group were significantly higher than those of the HC group, and $M D$ values of the HR group were significantly higher than those of the HC group. These higher CB-aCC MD values found in $\mathrm{SH}$ and $\mathrm{HR}$ may indicate myelinization damage within the aCC pathway, which may result in emotional dysregulation $(11,20)$.

In a meta-analysis of ten DTI studies conducted in adults with BD (33), two studies specifically reported decreased levels of FA in the CB-aCC and increased values of MD $(34,35)$. In a DTI tractography study

Table 4: Mean Diffusivity Values for the Anterior Cingulate Cortex ${ }^{a}$

\begin{tabular}{lccr} 
& Median values (Interquartile range) & $\mathbf{~ Z}$ & 0.837 \\
\hline SHR/AHR & $0.912(0.095) / 0.909(0.055)$ & -0.254 & $0.014(\mathrm{SHR}>\mathrm{HC})$ \\
SHR/HC & $0.912(0.095) / 0.873(0.018)$ & -2.068 & 0.037 \\
AHR/HC & $0.909(0.055) / 0.873(0.018)$ & -1.862 & $0.010(\mathrm{HR}>\mathrm{HC})$ \\
HR/HC & $0.909(0.073) / 0.873(0.018)$ & -2.360 & 0 \\
\hline
\end{tabular}

SHR: Symptomatic high risk group, AHR: Asymptomatic high-risk group, HC: Healthy control group, HR: High risk group, aMann Whitney-U test was used for data analysis, $\mathrm{p}<0.016$ was accepted as statistically significant after Bonferroni correction 
exploring pathways of white matter in patients with $\mathrm{BD}$, there was an observed statistical trend (although not statistically significant) towards lower FA levels within the cingulate cortexes of the case group subjects and in turn, higher MD levels in this group (36). A DTI study of 33 adult patients with BD compared to 40 healthy controls obtained lower FA values within the $\mathrm{CB}$-aCC (20). Another DTI study conducted among children and adolescents to evaluate early-onset $\mathrm{BD}$ and unipolar depression cases found lower FA and higher MD values for the $\mathrm{BD}$ group, specifically in the subgenual region of the CB-aCC (37). A study conducted in pediatric BD patients using gray matter voxel-based morphometry (VBM) and white matter tract-based spatial statistics (TBSS) methodology detected lower values of FA and higher values of MD within the CB-aCC (38).

A meta-analysis by Vederine et al. (2011) (33) also reported two other studies $(22,39)$ that described increased FA values, especially in the right $\mathrm{CB}-\mathrm{aCC}$, and decreased values of $\mathrm{MD}$. A review of the literature suggests contradicting results regarding $\mathrm{MD}$ and $\mathrm{FA}$ values of $\mathrm{CB}$-aCCs in $\mathrm{BD}$ cases, although only a limited number of studies covering this issue in a BD risk group sample exist. Regarding the pathophysiological mechanisms of $\mathrm{BD}$ (hyperactivation of related pathways through possible compensatory mechanisms caused by hyperstimulation of $\mathrm{aCC}$ ), we hypothesized that $\mathrm{MD}$ values of $\mathrm{CB}$-aCC would be lower in the high-risk individuals. Along with the findings in the literature, the results of our study contradict this hypothesis; however, our results are consistent with some other studies quoted above in this matter $(20,37)$.

This study was designed specifically for high-risk offspring of $\mathrm{BD}$ patients; therefore, the results found here may indicate the early signals of the disorder itself. It can be speculated that later in life, when these individuals happen to develop full-blown $\mathrm{BD}$, similar findings in DTI characteristics of $\mathrm{BD}$ may emerge. The statistical trend of $\mathrm{MD}$ values of $\mathrm{CB}-\mathrm{aCC}$ compared between AHR and HC becomes statistically significant when we compare MD values of SHR and HC. This may be an indicator of DTI findings emerging during the development of $\mathrm{BD}$.

Generalization of our findings to the entire BD risk group would not be appropriate, since we need to bear in mind possible limitations or methodological errors. One factor that might have affected this study is the child's or adolescent's history of psychotropic drug use in the past and/or at the time of assessment (Table 3 ). While a limited number of studies that evaluated direct effects of drug use on MD levels of specific brain regions exist, to the best of our knowledge, no study has explored a high-risk BD group with respect to this feature. However, it may be possible that drugs used for the purpose of medication could affect MD values in certain brain regions (for example; aCC, vPFC). Two reviews exploring the effects of drugs on brain structure in patients with BD reported that moodstabilizing agents (specifically lithium) increased graymatter volumes in the hippocampus, aCC, and amygdala $(40,41)$. However, none of these studies employed DTI. The limited and inconsistent nature of the literature indicates that further studies in this field are warranted.

Although we hypothesized FA differences between brain regions, none of the results were statistically significant. This result may have been due to the small sample size or methodological errors that might have arisen at the time of mask formations (which is explained in the method section) during ROI evaluation. The MD difference of $\mathrm{CB}-\mathrm{aCC}$ between groups is at a chance level; so it is hard to say if the null finding in the FA values of $\mathrm{CB}-\mathrm{aCC}$ is real or due to the small sample size. It is also important to consider the age differences between case and control groups, since the structure of certain brain regions (for example, aCC or Prefrontal Cortex) tend to change with age, independently of developing psychiatric disorders. However, to our knowledge, no studies have examined what these certain brain regions are, how they develop throughout the age span of $\mathrm{BD}$ emergence, or how they relate to $\mathrm{BD}$.

The Bipolar Offspring Study (BIOS) of Pittsburg University found that $75 \%$ of children whose parents had been diagnosed with BD met the criteria for BD-Not Otherwise Specified (BD-NOS) or major depressive disorder (MDD) before the age of 12 years (42). Other studies have shown that HR children may have subsyndromal manic symptoms that can disrupt functioning and quality of life as much as ten years before they are diagnosed with BD $(43,44)$. This study was initially designed to match the HR and HC groups by age. However, in accordance with the literature, we found that most of the subjects in the AHR group presented subsyndromal manic symptoms during the time of the study and had a diagnosis of MDD before the study took place (Table 3 ). These subjects were shifted into the SHR group, resulting in a lower mean age of the AHR group. The mean age in the AHR and HR groups is much lower than in the control group (Tables 1 and 2), which can be attributed to the development of psychiatric symptoms at an age as early 
as 10-12 years. This finding is important because it may reflect a possible onset period and developmental symptomatology for the concept of a prodromal period of BD.

Using DTI methods, we found that the SHR group of offspring of patients with BD had higher CB-aCC $\mathrm{MD}$ values than the $\mathrm{HC}$ group, which may be an indication of cellular damage. We also observed a statistical trend towards higher MD values in the AHR group compared to those in the HC group, which may be interpreted as the cellular damage being a process that starts at younger ages and continues throughout the development of BD. To our knowledge, this is the first DTI study that compares neuroimaging characteristics between AHR and SHR groups. Since this is a preliminary study, it needs to be pointed out that basic DTI analysis (FA, MD) of five brain regions should be taken further by analyzing radial and axial diffusions or using a tractography method. Regardless, the findings of this study add a perspective for a better understanding of the psychopathological processes in HR offspring, and potentially offer a means for an earlier diagnosis of BD. There is a great need for more longitudinal studies with larger sample sizes in this area to reach a better understanding of the pathophysiology of $\mathrm{BD}$ and to determine a psychiatric approach towards the HR offspring of patients with BD.

\begin{tabular}{|c|c|c|}
\hline \multicolumn{2}{|c|}{ Contribution Categories } & Author Initials \\
\hline \multirow{3}{*}{ Category 1} & Concept/Design & M.B., S.A.G., N.I.E. \\
\hline & Data acquisition & M.B., I.T.Y., H.G. \\
\hline & Data analysis/Interpretation & M.B., I.T.Y. \\
\hline \multirow{2}{*}{ Category 2} & Drafting manuscript & M.B., S.A.G., I.T.Y. \\
\hline & Critical revision of manuscript & N.I.E., H.G. \\
\hline Category 3 & Final approval and accountability & M.B., S.A.G., N.I.E., I.T.Y., H.G. \\
\hline \multirow{2}{*}{ Other } & Technical or material support & H.G. \\
\hline & Supervision & N.I.E. \\
\hline
\end{tabular}

Acknowledgements: Authors would like to acknowledge the valuable contributions of Ceren Unal from Dokuz Eylul University Radiodiagnostics Department to the conversion of DTI data, Professor Aysegul Ozerdem from Dokuz Eylul University Psychiatry Department to the design and Professor Jair Soares from University of Texas Department of Psychiatry and Behavioral Sciences regarding the DTI acquisition and processing period of the study.

Ethics Committee Approval: This study was approved by the Institutional Review Board (Ethics Committee) of Dokuz Eylul University School of Medicine (Izmir, Turkey).

Informed Consent: All parents of the children had given assent and written consent for the children to participate in the study as either healthy volunteers or case group members after the procedures had been fully explained.

Peer-review: Externally peer-reviewed.

Conflict of Interest: All authors declare conflicts of interest.

Financial Disclosure: This study was funded by Dokuz Eylul University Scientific Research Projects Coordination Unit, Izmir, Turkey.

\section{REFERENCES}

1. Craddock N, Jones I. Genetics of bipolar disorder. J Med Genet 1999; 36:585-594. [CrossRef]

2. Merikangas KR, Jin R, He JP, Kessler RC, Lee S, Sampson NA, Viana MC, Andrade LH, Hu C, Karam EG, Ladea M, MedinaMora ME, Ono Y, Posada-Villa J, Sagar R, Wells JE, Zarkov Z. Prevalence and correlates of bipolar spectrum disorder in the world mental health survey initiative. Arch Gen Psychiatry 2011; 68:241-251. [CrossRef]

3. Kessler RC, McGonagle KA, Zhao S, Nelson CB, Hughes M, Eshleman S, Wittchen HU, Kendler KS. Lifetime and 12-month prevalence of DSM-III-R psychiatric disorders in the United States. Results from the National Comorbidity Survey. Arch Gen Psychiatry 1994; 51:8-19. [CrossRef]

4. Mutlu C, Guvendeger-Doksat N, Erdogan A. Epidemiology in pediatric bipolar disorder. Current Approaches in Psychiatry 2015; 7:382-390. (Turkish) [CrossRef]

5. Hirschfeld RM, Lewis L, Vornik LA. Perceptions and impact of bipolar disorder: how far have we really come? Results of the national depressive and manic-depressive association 2000 survey of individuals with bipolar disorder. J Clin Psychiatry 2003; 64:161-174. [CrossRef]

6. Ghaemi SN, Sachs GS, Chiou AM, Pandurangi AK, Goodwin $\mathrm{K}$. Is bipolar disorder still underdiagnosed? Are antidepressants overutilized? J Affect Disord 1999; 52:135-144. [CrossRef]

7. Birmaher B, Axelson D, Strober M, Gill MK, Valeri S, Chiappetta L, Ryan N, Leonard H, Hunt J, Iyengar S, Keller M. Clinical course of children and adolescents with bipolar spectrum disorders. Arch Gen Psychiatry 2006; 63:175-183. [CrossRef]

8. Inal-Emiroglu F, Bozabali O. Diagnosis and differential diagnosis of bipolar disorder in children and adolescents. Turkish Journal of Child and Adolescent Mental Health 2002; 9:178-189. (Turkish)

9. Hauser M, Correll CU. The significance of at-risk or prodromal symptoms for bipolar I disorder in children and adolescents. Can J Psychiatry 2013; 58:22-31. [CrossRef]

10. Duffy A, Grof P, Robertson C, Alda M. The implications of genetics studies of major mood disorders for clinical practice. J Clin Psychiatry 2000; 61:630-637. [CrossRef]

11. Diler R, Uguz S, Seydaoglu G, Avci A. Mania profile in a community sample of prepubertal children in Turkey. Bipolar Disord 2008; 10:546-553. [CrossRef]

12. Duffy A, Horrocks J, Doucette S, Keown-Stoneman C, McCloskey S, Grof P. Childhood anxiety: an early predictor of mood 
disorders in offspring of bipolar parents. J Affect Disord 2013; 150:363-369. [CrossRef]

13. Le Bihan D. Looking into the functional architecture of the brain with diffusion MRI. Nat Rev Neurosci 2003; 4:469-480. [CrossRef]

14. O'Donnell LJ, Westin CF. An introduction to diffusion tensor image analysis. Neurosurg Clin N Am 2011; 22:185-196. [CrossRef]

15. Adler CM, Holland SK, Schmithorst V, Wilke M, Weiss KL, Pan H, Strakowski SM. Abnormal frontal white matter tracts in bipolar disorder: a diffusion tensor imaging study. Bipolar Disord 2004; 6:197-203. [CrossRef]

16. Adler CM, Adams J, DelBello MP, Holland SK, Schmithorst V, Levine A, Jarvis K, Strakowski SM. Evidence of white matter pathology in bipolar disorder adolescents experiencing their first episode of mania: a diffusion tensor imaging study. Am J Psychiatry 2006; 163:322-324. [CrossRef]

17. Frazier JA, Breeze JL, Papadimitriou G, Kennedy DN, Hodge SM, Moore CM, Howard JD, Rohan MP, Caviness VS, Makris $\mathrm{N}$. White matter abnormalities in children with and at risk for bipolar disorder. Bipolar Disord 2007; 9:799-809. [CrossRef]

18. Macritchie KA, Lloyd AJ, Bastin ME, Vasudev K, Gallagher P, Eyre R, Marshall I, Wardlaw JM, Ferrier IN, Moore PB, Young AH. White matter microstructural abnormalities in euthymic bipolar disorder. Br J Psychiatry 2010; 196:52-58. [CrossRef]

19. Wang F, Kalmar JH, He Y, Jackowski M, Chepenik LG, Edmiston EE, Tie K, Gong G, Shah MP, Jones M, Uderman J, Constable RT, Blumberg HP. Functional and structural connectivity between the perigenual anterior cingulate and amygdala in bipolar disorder. Biol Psychiatry 2009; 66:516-521. [CrossRef]

20. Wang F, Kalmar JH, Edmiston E, Chepenik LG, Bhagwagar Z, Spencer L, Pittman B, Jackowski M, Papademetris X, Constable RT, Blumberg HP. Abnormal corpus callosum integrity in bipolar disorder: a diffusion tensor imaging study. Biol Psychiatry 2008; 64:730-733. [CrossRef]

21. Ellison-Wright I, Bullmore E. Anatomy of bipolar disorder and schizophrenia: a meta-analysis. Schizophr Res 2010; 117:1-12.

22. Wessa M, Linke J. Emotional processing in bipolar disorder: behavioural and neuroimaging findings. Int Rev Psychiatry 2009; 21:357-367. [CrossRef]

23. Metzler-Baddeley C, Jones DK, Belaroussi B, Aggleton JP, O'Sullivan MJ. Frontotemporal connections in episodic memory and aging: a diffusion MRI tractography study. J Neurosci 2011;31:13236-13245. [CrossRef]

24. Phillips ML, Ladouceur CD, Drevets WC. A neural model of voluntary and automatic emotion regulation: implications for understanding the pathophysiology and neurodevelopment of bipolar disorder. Mol Psychiatry 2008; 13:833-857. [CrossRef]

25. McCrea SM. Bipolar disorder and neurophysiologic mechanisms. Neuropsychiatr Dis Treat 2008; 4:1129-1153. [CrossRef]

26. Houenou J, Wessa M, Douaud G, Leboyer M, Chanraud S, Perrin M, Poupon C, Martinot JL, Paillere-Martinot ML. Increased white matter connectivity in euthymic bipolar patients: diffusion tensor tractography between the subgenual cingulate and the amygdalohippocampal complex. Mol Psychiatry 2007; 12:1001-1010.
27. Torgerson CM, Irimia A, Leow AD, Bartzokis G, Moody TD, Jennings RG, Van Horn JD, Altshuler LL. DTI tractography and white matter fiber tract characteristics in euthymic bipolar I patients and healthy control subjects. Brain Imaging Behav 2013; 7:129-139. [CrossRef]

28. Versace A, Ladouceur C, Graur S, Acuff H, Bonar L, Monk K, McCaffrey A, Yendiki A, Leemans A, Travis MJ, Diwadkar VA, Holland SK, Sunshine JL, Kowatch RA, Horwitz SM, Frazier TW, Arnold LE, Fristad MA, Youngstrom EA, Findling RL, Goldstein BI, Goldstein T, Axelson D, Birmaher B, Phillips ML. Diffusion imaging markers of bipolar versus general psychopathology risk in youth at-risk. Neuropsychopharmacology 2018; 43:2212-2220.

29. First MB, Spitzer RL, Gibbon M, Williams JBW. Structured Clinical Interview for DSM-IV Axis I Disorders (SCID-I). Washington DC: American Psychiatric Press, 1997.

30. Kaufman J, Birmaher B, Brent D, Rao U, Flynn C, Moreci P, Williamson D, Ryan N. Schedule for Affective Disorders and Schizophrenia for School-Age Children-Present and Lifetime Version (K-SADS-PL): initial reliability and validity data. J Am Acad Child Adolesc Psychiatry 1997; 36:980-988. [CrossRef]

31. Geller B, Zimerman B, Williams M, Bolhofner K, Craney JL. Bipolar disorder at prospective follow-up of adults who had prepubertal major depressive disorder. Am J Psychiatry 2001; 158:125-127. [CrossRef]

32. Hillegers MH, Reichart CG, Wals M, Verhulst FC, Ormel J, Nolen WA. Five-year prospective outcome of psychopathology in the adolescent offspring of bipolar parents. Bipolar Disord 2005; 7:344-350. [CrossRef]

33. Vederine FE, Wessa M, Leboyer M, Houenou J. A meta-analysis of whole-brain diffusion tensor imaging studies in bipolar disorder. Prog Neuro-Psychopharmacology Biol Psychiatry 2011; 35:1820-1826. [CrossRef]

34. Benedetti F, Yeh PH, Bellani M, Radaelli D, Nicoletti MA, Poletti S, Falini A, Dallaspezia S, Colombo C, Scotti G, Smeraldi E, Soares JC, Brambilla P. Disruption of white matter integrity in bipolar depression as a possible structural marker of illness. Biol Psychiatry 2011; 69:309-317. [CrossRef]

35. Liu JX, Chen YS, Hsieh JC, Su TP, Yeh TC, Chen LF. Differences in white matter abnormalities between bipolar I and II disorders. J Affect Disord 2010; 127:309-315. [CrossRef]

36. Lin F, Weng S, Xie B, Wu G, Lei H. Abnormal frontal cortex white matter connections in bipolar disorder: a DTI tractography study. J Affect Disord 2011; 131:299-306. [CrossRef]

37. Serafini G, Pompili M, Borgwardt S, Houenou J, Geoffroy PA, Jardri R, Girardi P, Amore M. Brain changes in early-onset bipolar and unipolar depressive disorders: a systematic review in children and adolescents. Eur Child Adolesc Psychiatry 2014; 23:1023-1041. [CrossRef]

38. Gao W, Jiao Q, Qi R, Zhong Y, Lu D, Xiao Q, Lu S, Xu C, Zhang Y, Liu X, Yang F, Lu G, Su L. Combined analyses of gray matter voxel-based morphometry and white matter tract-based spatial statistics in pediatric bipolar mania. J Affect Disord 2013; 150:7076. [CrossRef]

39. Mahon K, Wu J, Malhotra AK, Burdick KE, DeRosse P, Ardekani BA, Szeszko PR. A voxel-based diffusion tensor imaging study 
of white matter in bipolar disorder. Neuropsychopharmacology 2009; 34:1590-1600. [CrossRef]

40. Hafeman DM, Chang KD, Garrett AS, Sanders EM, Phillips ML. Effects of medication on neuroimaging findings in bipolar disorder: an updated review. Bipolar Disord 2012; 14:375-410.

41. Phillips ML, Travis MJ, Fagiolini A, Kupfer DJ. Medication effects in neuroimaging studies of bipolar disorder. Am J Psychiatry 2008; 165:313-320. [CrossRef]

42. Birmaher B, Axelson D, Monk K, Kalas C, Goldstein B, Hickey MB, Obreja M, Ehmann M, Iyengar S, Shamseddeen W, Kupfer D, Brent D. Lifetime psychiatric disorders in school-aged offspring of parents with bipolar disorder. Arch Gen Psychiatry 2009; 66:287-296. [CrossRef]

43. Luby JL, Navsaria N. Pediatric bipolar disorder: evidence for prodromal states and early markers. J Child Psychol Psychiatry 2010; 51:459-471. [CrossRef]

44. Carlson GA, Findling RL, Post RM, Birmaher B, Blumberg HP, Correll C, DelBello MP, Fristad M, Frazier J, Hammen C, Hinshaw SP, Kowatch R, Leibenluft E, Meyer SE, Pavuluri MN, Wagner KD, Tohen M. AACAP 2006 Research Forum Advancing research in early-onset bipolar disorder: barriers and suggestions. J Child Adolesc Psychopharmacol 2009; 19:312. [CrossRef] 